\title{
Komputerowe symulowanie procesu spawania przy zginaniu z wykorzystaniem oprogramowania Marc/Mentat
}

\author{
Computer welding simulation under bending \\ using Marc/Mentat software
}

\section{Streszczenie}

W pracy przedstawiono podstawowe możliwości wspomagania procesu projektowania złączy spawanych wraz z analizą siły gnącej z wykorzystaniem oprogramowania MSC Marc/ Mentat. Program ten może być używany do obliczania naprężeń i odkształceń w zakresie liniowo-sprężystym i nieliniowym.

Słowa kluczowe: spawanie; MES; spoina; zginanie

\section{Abstract}

The paper presents the basic possibilities of using MSC Marc/Mentat for computer aided welding simulation, with additional bending force. The software may be used to calculate stresses and strains in the linear-elastic and nonlinear range.

Keywords: welding; FEM; welds; bending

\section{Wstęp}

Aktualnie w przedsiębiorstwach coraz częściej wykorzystuje się komputerowe wspomaganie procesu spawania, szczególnie na etapie projektowania. Jest to motywowane chęcią wsparcia procesu spawania, czyli analizą naprężeń i odkształceń występujących podczas procesu spawania, która ma istotny wpływ na trwałość złącza. Podczas analizy numerycznej należy pamiętać, że uzyskane wyniki powinny zostać zweryfikowane doświadczalnie. Obliczenia numeryczne są szczególnie ważne w przemyśle wykorzystującym skomplikowane procesy montażowe, podczas których elementy poddawane spawaniu po krótkim czasie są obrabiane mechanicznie lub poddawane procesowi montażu. Dzieje się tak między innymi w procesie spawania ram samochodowych na linii montażu bądź w procesie produkcji wałów napędowych, kiedy po korekcji wyważania wał jest na końcach osadzany przegubowo.

Celem pracy jest przedstawienie oprogramowania MSC Marc/Mentat i jego możliwości do symulowania procesu spawania.

\section{Przegląd dostępnych rozwiązań}

Aktualnie na rynku funkcjonuje kilka rozwiązań Computer Aided Engineering pomagających projektować połączenia spawane. Do najpopularniejszych systemów CAE, oprócz Marc/Mentat, należą między innymi Simufact Welding, marki MSC. Wykorzystują one rozwiązanie Marca i są bardzo przyjazne dla użytkownika w kontekście interfejsu, pozwalając jednocześnie na zaawansowane analizy procesu spawania oraz jego szybkie prototypowanie. Proste analizy możliwe są do wykonania w oprogramowaniu ABAQUS oraz w większości popularnych systemów CAD, z uwzględnieniem jednak modelu ideowego i rozkładu naprężenia bez realizowania obliczeń termicznych. Do ciekawych rozwiązań również należy code_aster, który jest rozwijany przez francuską firmę państwową Électricité de France będącą dostawcą energii elektrycznej we Francji. Pozwala on na badanie procesów spawania wielościegowego oraz na implementacje przemian fazowych, ale jest środowiskiem, które wymaga doświadczenia w użytkowaniu oraz interpretacji wyników analizy metody elementów skończonych (MES). Interesującym rozwiązaniem do rozważania procesów spawalniczych są rozwiązania dystrybuowane przez Larsa-Erika Lindgren z Luleå Tekniska Universitet w Szwecji. Profesor Lindgren jest obecnie jednym z najbardziej zaangażowanych naukowców z dziedziny komputerowej symulacji spawania i stworzył subprogram CWMLab [1], który jest oparty na Matlabie. Program ten pozwala analizować procesy spawania elementów przestrzennych 3D.

\section{Opis programu}

Oprogramowanie Marc/Mentat firmy MSC jest kompletnym zestawem preprocesora, solvera oraz post procesora. Jest to jedno z najlepszych środowisk inżynierskich

Inż. Grzegorz Fiuk, dr hab. inż. Dariusz Rozumek, prof. PO - Politechnika Opolska.

Autor korespondencyjny/Corresponding author. fiuk.grz@gmail.com 
wykorzystywanych do obliczeń nieliniowych. Interfejsem graficznym użytkownika (GUI) przeznaczonym do wstępnego (pre-processing) i końcowego przetwarzania (postprocessing) jest MENTAT (rys. 1) [2]. Program ten pozwala na tworzenie geometrycznego modelu oraz jego edycję. Istnieje możliwość pracy na modelach przestrzennych 3D, płaskich shellach 2D oraz cienkich blach. Rozbudowana konfiguracja modelu pozwala na pokrycie go siatką mesh według potrzeb użytkownika. Przygotowanie modelu może się odbyć też poza MENTATem, ponieważ istnieje możliwość importowania plików geometrycznych STL, IGES i popularnych formatów CAD czy modeli przygotowanych w innych pre-processorach jak NASTRAN/ABAQUS. Jest to zalecana ścieżka pracy z powodu znacznie większej wydajności i jakości, szczególnie ze skomplikowanymi modelami przestrzennymi.

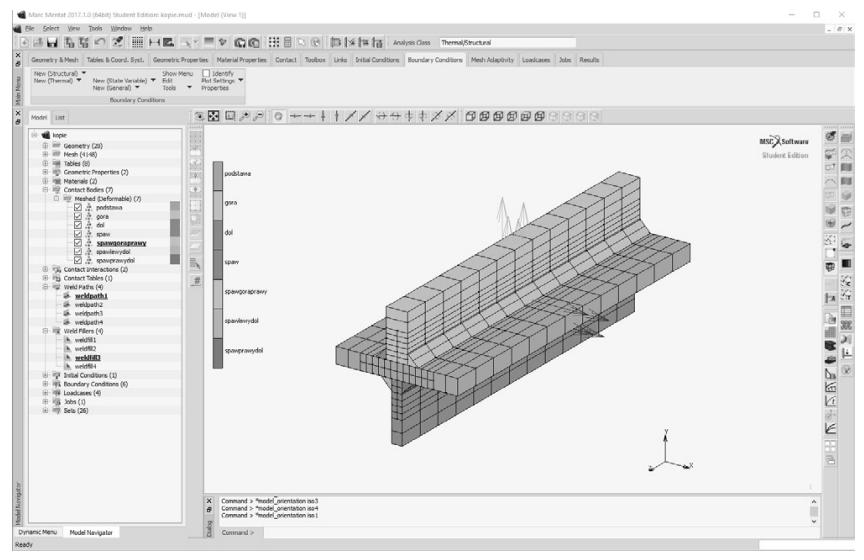

Rys. 1. Interfejs graficzny Mentat

Fig. 1. GUI of Mentat

Sam program posiada własną bazę materiałową, jednak jego istotnym walorem jest możliwość wprowadzenia materiałów niestandardowych, takich jak specjalistyczne stale stopowe, wysokogatunkowe stopy aluminium, tytan czy platery. Jedną z najważniejszych zalet środowiska Marc/ Mentat w zakresie materiałowym jest możliwość zaawansowanej parametryzacji właściwości materiałowych, łącznie z możliwością implementowania przemian fazowych stopu. Materiały mogą być rozpatrywane jako obiekty o zachowaniu liniowym oraz nieliniowym w zależności od potrzeb użytkownika. Oprogramowanie MSC pozwala na wykorzystanie rozbudowanej biblioteki modeli (elementów) potrzebnych do budowania siatki mesh. Elementy mogą posiadać od 3 do 21 węzłów z różnymi możliwościami oddziaływania między sobą. Model w preprocessingu jest parametryzowany co do warunków brzegowych. Do kwestii kluczowych należy opis utwierdzeń, ustawienia brzegowych temperatur modelu czy stref kontaktowych w zakresie bliskich układów. Cechy kontaktowe są dość szczegółowo parametryzowane w postaci budowy i sposobów oddziaływania poszczególnych elementów modelu, ich właściwości oraz oddziaływania poszczególnych części modelu z innymi elementami przy konkretnej charakterystyce kontaktowej. Zagadnienia spawalnicze opisywane są głównie za pomocą funkcji WELDPATH, WELDFILLER oraz WELDFLUX [2]. Funkcja WELDPATH odpowiada za trajektorie ruchu źródła mocy traktowanego jako źródło ciepła. Może być sterowana konkretnymi węzłami (nodami), krzywymi, bądź instrukcją stworzoną przez użytkownika. WELDFILLER pozwala określić zachowanie spoiwa w funkcji temperatury inicjacji oraz ewentualnie czas uruchomienia w przypadku skomplikowanych ścieżek spawania bądź modelowania wielościegowego. Finalnie źródło ciepła modelowane jest za pomocą opcji WELD FLUX (w przypadku przedstawianego tu rozwiązania w wersji objętościowej VOLUME), gdzie zgodnie z propozycją Goldaka [2,3] przyjmuje się podwójną elipsoidę za kształt źródła ciepła (rys. 2):

$$
\begin{aligned}
& q_{f}(x, y, z)=\frac{6 \sqrt{3} f_{f} Q}{a b c_{f} \pi \sqrt{\pi}} \exp \left(\frac{-3 x^{2}}{a^{2}}\right) \exp \left(\frac{-3 y^{2}}{b^{2}}\right) \exp \left(\frac{-3 z^{2}}{c^{2}}\right) \\
& q_{r}(x, y, z)=\frac{6 \sqrt{3} f_{r} Q}{a b c_{r} \pi \sqrt{\pi}} \exp \left(\frac{-3 x^{2}}{a^{2}}\right) \exp \left(\frac{-3 y^{2}}{b^{2}}\right) \exp \left(\frac{-3 z^{2}}{c^{2}}\right)
\end{aligned}
$$

gdzie:

$\mathrm{Q}$ - jest mocą energi spawania,

a, b, $c_{r}, c_{f}$ - są wymiarami przestrzennymi źródła,

$f_{r}, f_{f}-$ to wartości bezwymiarowe obliczane $z$ wzorów:

$$
f_{f}=\frac{2}{\left(1+\frac{c_{r}}{c_{f}}\right)} \quad f_{r}=\frac{2}{\left(1+\frac{c_{f}}{c_{r}}\right)}
$$

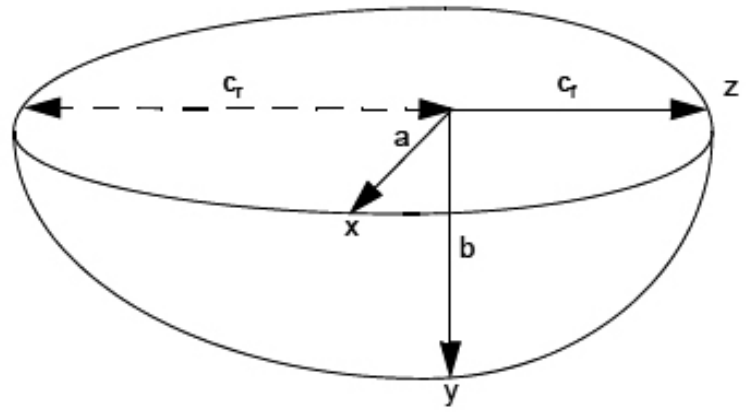

Rys. 2. Model źródła ciepła proponowany przez Goldaka Fig. 2. Goldak heat source model

Parametry spawania mogą być sterowane dość szczegółowo z użyciem podprogramów tworzonych przez użytkownika (subroutine), które pozwalają na własnoręczne sterowanie parametrami WELDPATH, WELDFILLER i WELDFLUX. Możliwe jest również wykorzystanie modelu cylindrycznego źródła ciepła używanego przy symulacji spawania laserowego.

Sam proces spawania może być lokalnie wspierany przez adaptacyjne regenerowanie (remeshowanie) siatki w rejonie aktualnie przemieszczającego się źródła mocy [2]. Najpopularniejszymi rozwiązaniami dla połączeń spawanych są dwa warianty: wejścia w geometryczny rejon oddziaływania źródła wraz z sąsiadującymi elementami (Nodes in Box) albo wzrostu gradientu temperatury $\mathrm{w}$ lokalnym układzie źródła mocy.

\section{Opis symulacji}

Do symulacji wykorzystano oprogramowanie MSC Marc/ Mentat, z licencją w wersji studenckiej (ograniczenie elementów/nodów do 5000, brak możliwości obliczeń z użyciem wielu rdzeni), zamodelowano połączenie doczołowe ukosowane na V, z dwóch blach gatunku 1.7337 o wymiarach $10 \times 50 \times 100 \mathrm{~mm}$. Parametry spawania dobrano z karty technologicznej oraz literatury [2,3], jednak zrezygnowano z modelowania spoiny dwuściegowej (wymaganej w rzeczywistości dla tej grubości blachy) z powodu ograniczeń obliczeniowych licencji studenckiej, zamiast tego przyjęto połączenie jednościegowe jako ideowe dla tego schematu połączenia. Płyty utwierdzono w osiach X, Y, Z na krańcowych częściach modelu, temperaturę początkową modelu ustawiono na $30{ }^{\circ} \mathrm{C}$. Dla płyty lewostronnej zastosowano lokalny remeshing w trybie węzłów w rejonie jeziorka spawalniczego (Node in Weld Pool Region), a symulację zamodelowano dla czasu 500 s. Następnie w czasie 10 s, poddano płytę zginaniu w środkowej części modelu siłą F -50 kN w kierunku osi Y. Schemat warunków brzegowych dla zginania przedstawiono na rysunku 3. 


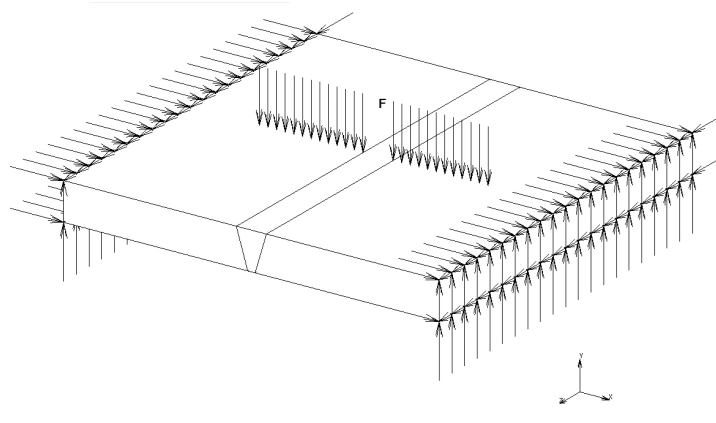

Rys. 3. Warunki brzegowe dla utwierdzenia i siły $F$

Fig. 3. Structural boundary conditions and applicated force $F$

\section{Wyniki symulacji i ich analiza}

Wyniki symulacji przedstawiono na rysunkach $4 \div 6$. Rysunek 4 ilustruje rozkład pola temperatury w czasie $20 \mathrm{~s}$ od rozpoczęcia procesu spawania. Analiza naprężeń zredukowanych wg Hubera-Missesa po skończonym procesie spawania, z wyłączeniem spoiwa, została przedstawiona na rysunku $5 \mathrm{a}$ i rysunku 5b. Przedstawiono na nim dwie płyty prawą (rys. 5a) i lewą (rys. 5b). Płyta lewa została przedstawiona z regenerowaną siatką mesh dla strefy wpływu ciepła, która ma wpływ na dokładność wyników w porównaniu z prawą płytą. Kumulacja naprężeń występuje w okolicy strefy wpływu ciepła oraz przy utwierdzeniu płyt. Rysunek 6 przedstawia odkształcenie płyt po zginaniu w kierunku osi $Y \mathrm{z}$ widocznym maksymalnym przemieszczeniem dochodzącym do $5 \mathrm{~mm}$.

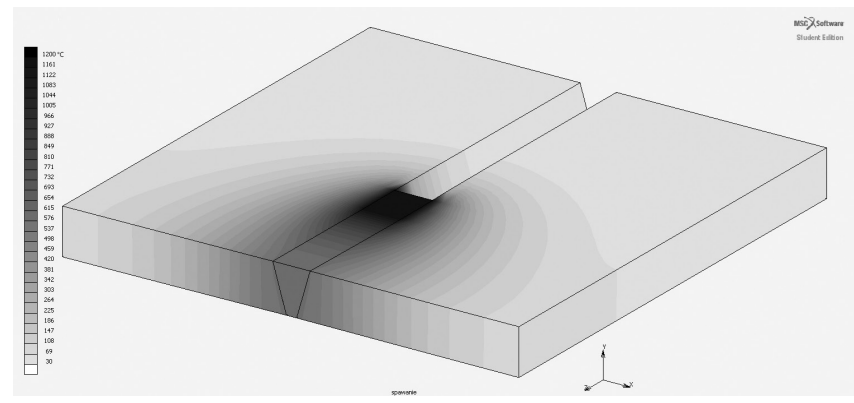

Rys. 4. Rozkład temperatur w procesie spawania Fig. 4. Temperature distribution in the welding process

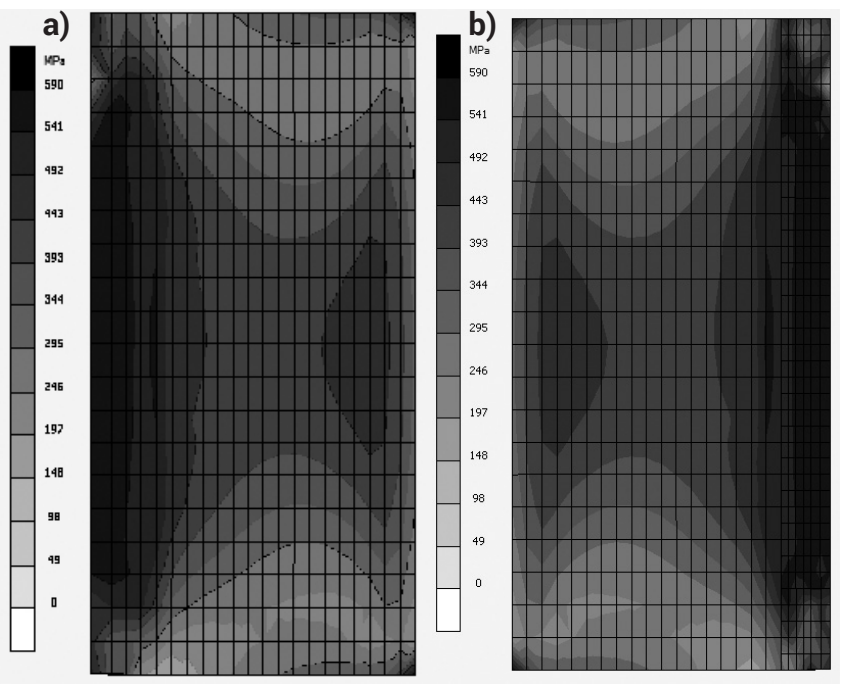

Rys. 5. Rozkład naprężeń wg Hubera-Missesa: a) widok z góry, b) z widoczną zregenerowaną siatką mesh (widok z góry)

Fig. 5. Stress distribution according to Huber-Misses: a) top view, b) with visible regenerated mesh (top view)

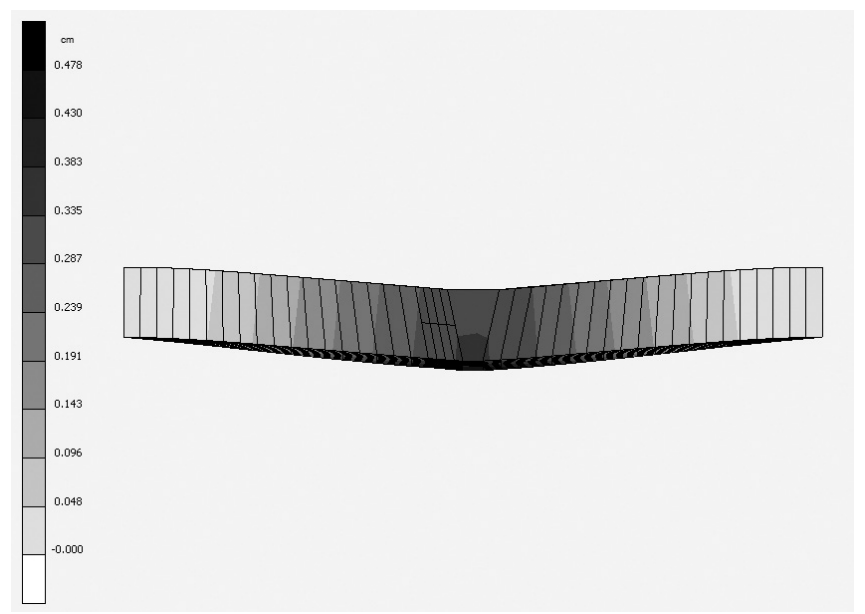

Rys. 6. Przemieszczenie przy zginaniu płyty po spawaniu w kierunku osi Y

Fig. 6. Displacement under bending the plate after welding in the direction of the $Y$ axis

\section{Podsumowanie}

Na podstawie przeprowadzonej symulacji zginania podczas procesu spawania sformułowano następujące wnioski:

1. Możliwe jest użycie oprogramowania MSC Marc/Mentat do symulowania procesów spawania.

2. Dokładniejsze wyniki rozkładu naprężeń uzyskano dla płyty lewej poddanej regeneracji siatką mesh (rys. 5).

\section{Literatura}

[1] Lindgren L.E., Computational Welding Mechanics, Woodhead Publishing, 2007.

[3] Goldak J. A., Mehdi A., Computational Welding Mechanics, Springer US, 2010.

[2] Marc Volume A, Theory and User Information, MSC Software Corporation, 2017. 